\title{
Educational Tool for the Qualitative Analysis of Electric Field Phenomenon
}

\author{
Jimmy W. Ramírez-Cano* and William Manuel Mora Penagos \\ Universidad Pedagogica Nacional, Bogota-Colombia Universidad Distrital Francisco Jose de Caldas, \\ Bogota-Colombia, Interinstitutional Doctorate in Education (DIE-UPN), Colombia; \\ jwramirez@pedagogica.edu.co,wmora@udistrital.edu.co
}

\begin{abstract}
Objectives: To propose an alternative didactic of the electrical phenomenon teaching, using Information and Communication Technologies (ICT). Methods: As a methodology for the development of the tool, a prototype-oriented development methodology was used. Findings: The built tool is based on an Augmented Reality system (AR) that uses interactive projections. This system consists of a structure that allows you to view the graphic information that will be projected on a table. The didactic alternative is proposed to meet the teaching-learning difficulties that are presented to guide the phenomenon of electrical fields and as an alternative to the teaching methodologies that emphasize in memorization of concepts. Application: For the use of the tool, some guidelines were developed according to the objectives of each activity. In addition, some questions were proposed to guide student learning and group discussion. It is important to highlight that the results obtained can be used for the development of didactic materials in other areas related to the phenomenon, as well as in other areas of knowledge and fields related to engineering. The tool built is part of the reflection on the didactics of technology, an academic discussion that is part of the doctoral thesis of the author of this document.This paper belongs to an academic discussion that takes part of the doctoral thesis of the first author of this document, under the direction of the second author.
\end{abstract}

Keywords: Augmented Reality (AR), Constructivism, Education, Electric Fields, Learning, Teaching Strategies

\section{Introduction}

The electrostatic phenomenon present in some physics courses proposes learning difficulties which prevent that the student relates the topic field vector with the phenomenon of electric fields ${ }^{1}$. For this reason, the topic is considered to be a source of great difficulty for learning in students in higher education level. In addition, the "limited papers that exist on learning difficulties in this area for university level" make relevant inquiry in this regard ${ }^{2}$. One reason for this difficulty is that students are not familiar with the physical phenomenon associated with the electric fields and, at the same time, this prevents the student to develop a connection with the mathematical formalism which explains the phenomenon. To be familiar with the phenomenon and be able to carry out the mathematical association is important; this will help to understand the issue of vectors, essential for the Gauss' law teaching ${ }^{3}$.

Another difficulty of learning shows that "the graphical representation of the field, through field lines, rise confusion among students who tend to materialize them as "tubes of force" by attributing a "real" character and do not consider them as graphics models made by scientists", to give an explanation of the analyzed phenomenon. As a result, the student settles for the resolution of integrals concerned to mathematical problems which are submitted, reducing the process that involves the relationship and understanding of the phenomenon to a methodical and rote learning.

A further difficulty lies in the ability of some institutions to equip each student in the classroom with the

${ }^{*}$ Author for correspondence 
right scientific instruments, required for the pilot activity development. This difficulty is that in many cases the teacher focus on speech activities that are supported with taskswhichare oriented to the rote learning of results. Consequently, it is offered to the student an image of science as finished in which he does not have an active participation.

Nowadays, many classroom activities developed by the students are focused on memorizing what science has already inquired. However, as an alternative to results rote learning, it is proposed a low-cost teaching tool that enables the student's interaction with the phenomenon under study. This proposal is aimed at improving the levels of understanding in the classroom, by favoring the deep and analytical observation of what is presented to the student. The alternative teaching pretends to bring students to a learning style that allows them to generate explanations and questioning about what they observeat the time of sharing with the group of work. It can be said that the didactic alternative is part of the way in which we understand ${ }^{4}$.

This work is part of the constructivist approach that some science didactic movements propose as an alternative to the methods that privilege memorization. This approach is aimed at restoring the meaning of scientific and technological education, by proposing activities which lead tothe students' active construction of their own representations $s^{5,6}$. The proposed activities allow the students to build their knowledge between structures and delimited knowledge frameworks, which guide them through their own experience construction ${ }^{2}$.

In the knowledge building about the electric fields phenomenon, it is advisable that the student interacts with the object of learning. This leads to thinking about the need to employ the scientific instrument in the experimental activity with a different look to the demonstration of results that can be found in the texts ${ }^{7}$. As a result, this look will allow linking epistemological aspects of science and technology in the construction of scientific and technological knowledge. In addition, it will enable the student to perform an in-depth analysis in the concept building8.

\section{Discussion}

The situations described above become a valuable reason to have a didactic tool for the phenomenon teaching. This tool will be placed on the theoretical activity and experimental laboratory activity. In other words, it is not intended to replace the experimental activity but give strength to the theory-experiment relationship. In addition, to provide a space that will help the student to develop their own explanations for the phenomenon of electrical fields?.

For the tool development, a system of Augmented Reality (AR) based on interactive projections is usedas shown in Figure 1. This system consists of a structure that allows viewing the graphical information that will be projected on a table. This information may change dynamically according to the objects that are placed on the table ${ }^{10}$. In relation to the operation, artificial vision algorithms used on images of depth. With these algorithms, it can be detected and where objects are on the table ${ }^{10}$. In relation to the operation, artificial vision algorithms are used on images of depth. With these algorithms it can be detected which and where objects are on the table. The software used for this purpose is Mat Lab; as input, a 3d camera Kinect (Windows) is connected and as output, a video beam. With the image obtained from the Kinect, a graph is generated which it will be projected on the table. It is important to mention that this system changes in real time, in other words, if the objects are moved, the information from the graphic changes according to this movement, therefore, the projection will do it, too.

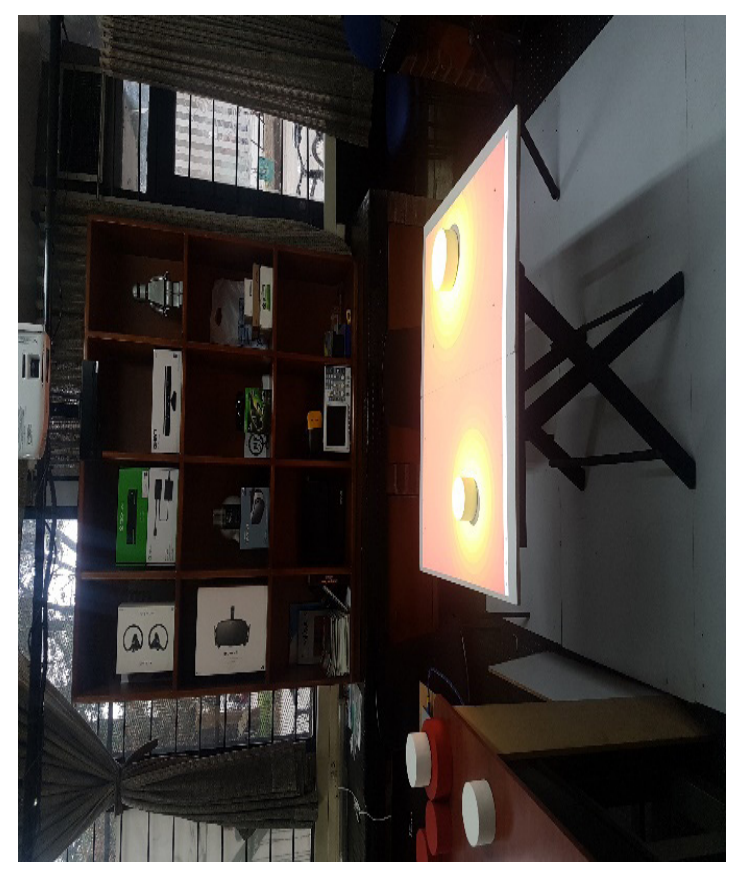

Figure 1. Augmented reality system built. 
The process described is considered to be highly interactive understanding that objects can be manipulated by the students following their instinct and supported with the indications of an elaborate plan ${ }^{11}$ that aims the student at answering questions that have been carried out to support the theoretical sessions and link them with the practical activities. Those questions take as reference the studies based on the methodology of teaching-oriented research, specific to the didactics of science ${ }^{12}$.

An item to highlight in the tool is that the student can change as many times as he wants, the elements and load a new activity only with running the program previously designed, which saves time to give an answer to the questions that are posed. Moreover, it prevents the movement of laboratory equipment that may pose a risk to him or his classmates. Within the field of teaching technology, the tool provides the student notions of control that are very useful for understanding other phenomena associated with this discipline. In addition, the student is provided with qualitative type information.

This new qualitative information of the phenomenon encourages him to build explanations and answer questions of aspects that bring his previous ideas and to make new; besides, it encourages him to think of alternatives to measure the phenomenon under study ${ }^{8}$. The explanations and answers to the questions built by the student, become a powerful tool that allowsrepresenting and codifying the understanding and explanation of the phenomenon, facilitating the elaboration of new questions and the possibility of generating predictions and assumptions about the behavior of the phenomenon. These new encodings are considered a new learning that improves what he brings in their previous ideas, as a result, the tool promotes the understanding of the models that science has been improving over the years ${ }^{13}$, and this is a way of bringing the knowledge that science has generated, to technology.

\section{Methodology}

For the development of the tool, an oriented-prototype development methodology was used. This methodology allows a prototype permanent review, adjusting it to the requirements and objectives, for this reason, it can guarantee the compliance of the targets ${ }^{14}$. The method allowed adapting the different levels of the system, necessary for the prototype building, an activity that is complicated because these levels evolve with experience. To use this methodology provided the tool refinement over the course of the project.

\section{Results}

The proposed activities have been organized to address the electrostatic phenomenon, necessary for the Gauss' law understanding. The topics developed are force and electric field, electric flow, electric potential, electric potential energy, potential difference, electrical equipotential lines and the condenser. Each activity consists of two stages: The first presents the guidelines for the use of the tool, a series of exercises and indications are handed in (to the student), which are organized according to the objective of the activity. The second stage presents activities of discussion in which are formulated questions that mediate the learning process. Moreover, it raises concerns for the teacher to organize the discussion of ideas with the students. These stages improve the creation of explanations in the group, taking into account what is observed with the tool. Regarding this proposal, learning is dynamic and keeps a contextual connection, which facilitates the conceptual and epistemological change with the active participation of each group $p^{7,8}$.

The following are some projections with the tool. Figure 2(a) shows the lines of force projected on the table of two bodies of different sizes. The bodies in the tool are interpreted as electrical charges and the size of them is related

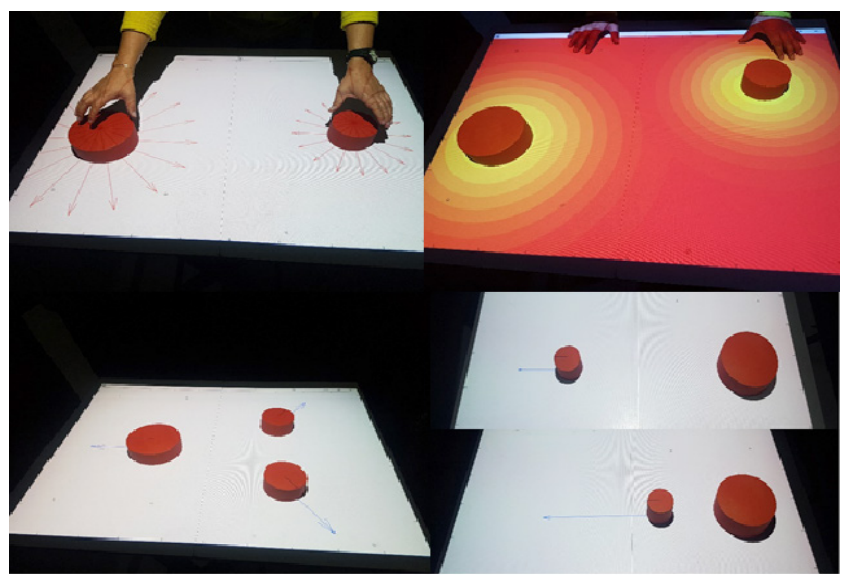

Figure 2. Examples of projections with the tool. From left to right: (a) Lines of force of two loads. (b) Electric field exerted by two loads. (c) Lines of force resulting from the interaction between three loads. (d) Electrical potential of a test load approached at a higher magnitude. 
to the amount of load contained by themselves, for this reason, it is possible to assume the magnitude of the vector field in relation to the size of the bodies. Figure 2(b) projects an image of the field exerted by two loads of different magnitude. Figure 2(c) projects the lines of force resulting from the interaction of three loads; one of them has a different magnitude of load to the others. Figure 2(d) shows two stages at which a test load is approached to a load of greater magnitude. Note that the electrical potential of the test load increases as it gets closer to the other load.

\section{Conclusions}

The activities designed and the system built are considered a contribution to the science and technology didactic, in view of the fact that in the knowledge building process the student is encouraged to develop an explanation of what was observed. To respond to the suggested questions, the student is motivated to interact with the theoretical concepts. In addition, it allows him to connect the procedural skills of the experimental activity with the ideas that he brings about the phenomenon under study and, not less important, it allows the teacher to ask about how he reasons with these ideas. These are some of the aimspursued by science education. Offering the student a qualitative behavior of the phenomenon approaches him to a qualitative experience. Coupled with the group discussion on the explanations built, it approaches the group to a process on how knowledge has been built in the sciences and offers a different learning alternative to the contents memorization.The tool is part of an ongoing process of reflection on technology teaching. It is not considered a final product; on the contrary, this work belongs to an academic discussion that takes part of the doctoral thesis of the first author of this document, under the direction of the second author.

\section{References}

1. Sandra V, Julia S. Comprensión de los conceptos de campo, energía y potencial electricosy magnéticos en estudiantes universitarios. Revista Brasileira de Ensino de Fisica. 2001 Sep; 23(3):308-18. Crossref

2. Jenaro G, Julia S, Sandra V. Analisis de los Procesos de Aplicacion de las Leyes de Gauss y Ampere por Estudiantes
Universitarios de Espana y Argentina. Revista Brasileira de Ensino de Fisica. 2003; 25(2):195-206. Crossref

3. Daniel L, Gregory H. A simple electric field probe in a Gauss's Law Laboratory. The Physics Teacher. 2006; 44:470-2. Crossref

4. Richardy W, Richard G. Probing understanding, cap. The nature of understanding. Routledge; 1999. p. 1-15.

5. Isabel M. Formacao de profesores de fisicaequimica sobre a tecnología e suasrelacoes socio-científicas. Revista electronica de ensenanza de las ciencias. 2003; 2(3):293-308.

6. Ángel V, Josey A, Maria M. Masalla de la ensenanza de las ciencias para científicos: hacia una educacion científica humanística. Revista Electrónica de Ensenanza de las Ciencias. 2005; 4(2):1-30.

7. Jose M, Sandray S, Maria A. La actividad experimental: Construccion de fenomenologías y procesos de formalizacion. Praxis filosofica. 2013; 36:119-38.

8. Angely R, Yirsen A. La experimentacion y el desarrollo del pensamiento físico; un analisis historico y epistemologico fines didacticos. Investigacion y Educacion. Universidad de Antioquia; 2013. p. 1-5.

9. Pirker J, Lesjak I, Guetl C. Maroon VR: A room-scale physics laboratory experiencia. IEEE 17th International Conference on Advanced Learning Technologies. 2017. p. 482-4. Crossref

10. Hu L, Wang M, Song Z. A convenient method of video seethrough augmented reality based on image-guided surgery system. Proceedings of the 7th International Conference on Internet Computing for Engineering and Science (ICICSE); Shanghai. 2013. p. 100-3. Crossref

11. Bower M, Howe C, McCredie N, Robinson A, Grover D. Augmented reality in Education - Cases, places, and potentials. Proceeding IEEE 63rd Annul Conference. International Council for Educational Media, ICEM; 2013. p. 1-11.

12. Carlesy F, Jenaro G. La ensenanza del concepto de campo electrico basada en un modelo de aprendizaje como investigación orientada. Ensenanza de lasCiencias. 2001; 19(2):319-34.

13. Christina H. Models in Physics, models for Physics learning, and why the distinction may matter in the case of electric circuits. Research in Science Education. 2008; 38:529-44. Crossref

14. Knight LV, Theresa SA, Kellen V. System development methodologies for web-enabled e-business: A customization framework. IGI International Gemological Institute Chennai Global; 2003. p. 213-26. Crossref 